\title{
LETRAMENTOS LITERÁRIOS: O QUE SE AVALIA NO EXAME NACIONAL DO ENSINO MÉDIO?
}

\author{
Tatiana Simões e Luna* \\ Universidade Federal Rural de Pernambuco (UFRPE) \\ Beth Marcuschi** \\ Universidade Federal de Pernambuco (UFPE)
}

RESUMO: Este trabalho analisa as questões da prova do Exame Nacional do Ensino Médio - ENEM 2013 relativas à literatura, verificando que conhecimentos literários estão sendo avaliados e exigidos do aluno no fim da educação básica. Interessa-nos refletir sobre o lugar ocupado pela literatura nessa avaliação, considerando que esta reflete e refrata o que vem sendo feito na educação brasileira nos últimos anos. Para tal, discutimos a didática ancorada na cronologia e a voltada para o letramento literário, com base principalmente nos estudos de Cereja (2005), Cosson (2009), Rouxel (2013) e nas OCNEM (BRASIL , 2006). Os resultados sinalizam alguns avanços, pois a prova recobre obras da literatura contemporânea, inclusive exemplos transgressores das convenções linguísticas, e propicia o diálogo com outras semioses. No entanto, a maioria das questões realiza uma abordagem inadequada do texto, tomando-o como pretexto para avaliar a compreensão textual ou o saber sobre conteúdos linguístico-estilísticos.

Palavras-chaves: Ensino de literatura. ENEM. Letramento literário. Avaliação.

http://dx.doi.org/10.1590/0102-4698135569

"Doutoranda em Linguística pela Universidade Federal de Pernambuco (UFPE). Professora Assistente do Departamento de Educação da Universidade Federal Rural de Pernambuco (UFRPE). Membro do LIFE Laboratório Interdisciplinar de Formação de Educadores (DEB/CAPES - UFRPE). E-mail: tsluna@yahoo.com.br "* Doutora em Linguística pela Universidade Federal de Pernambuco (UFPE). Professora Associada do Departamento e do Programa de Pós-Graduação em Letras da Universidade Federal de Pernambuco (UFPE). Coordenadora do Núcleo de Avaliação e Pesquisa Educacional da Universidade Federal de Pernambuco (NAPE). E-mail: bethmufpe@gmail.com 


\title{
LITERARY LITERACIES: WHAT IS EVALUATED IN THE NATIONAL HIGH SCHOOL EXAM?
}

\begin{abstract}
This paper discusses the issues of the National High School Exam test - ENEM 2013 relating to literature, finding what literary knowledge is being evaluated and required by the student at the end of basic education. Interested in reflecting about the place occupied by this literature evaluation, considering that it reflects and refracts what is being done in Brazilian education in recent years. To this end, we discuss the teaching anchored in chronology and toward the literary literacy, based primarily on studies of Cereja (2005), Cosson (2009), Rouxel (2013) and the OCN (2006). The results indicate some progress, because the test covers the works of contemporary literature, including examples of linguistic convention transgressions, and promotes dialogue with other semiosis. However, most questions perform an inadequate approach to the text, taking it as a pretext to assess reading comprehension or to know about linguistic and stylistic content.
\end{abstract}

Keywords: Teaching literature. ENEM. Literary literacy. Evaluation.

\section{INTRODUÇÃO}

A Linguística Aplicada (doravante LA) surgiu como uma disciplina voltada para a aplicação das teorias linguísticas à descrição e ao ensino de línguas. Desde fins da década de 1980, contudo, diversos estudos buscam a ruptura com esse velho paradigma, propondo a definição de propósitos e a adoção de métodos próprios, distintos dos da chamada Linguística scrito sensu, mas que levam em conta a linguística em sentido macro. A LA hoje reconhece a contribuição de outras áreas do conhecimento que também problematizam a linguagem, como a educação, a psicologia cognitiva, a comunicação, a antropologia e a sociologia, e se volta para o estudo de práticas discursivas para além dos contextos escolares.

Rompendo com os postulados positivistas de universalidade, de objetividade e preditibilidade, a LA constrói teorias e métodos com base no entrecruzamento de saberes de outras disciplinas a fim de melhor compreender os problemas sociais em que a linguagem tem um papel central. Moita-Lopes (2009) argumenta que, mais que interdisciplinar, a LA assumiu uma feição "indisciplinar": ela não está em busca da verdade ou da confirmação/refutação de uma teoria, mas admite que as formas de fazer pesquisa são também "formas de fazer política ao se tematizar o que não é tematizado e ao dar a voz a quem não tem" (MOITA-LOPES, 2009, p. 22).

É nessa perspectiva que viemos explorar um tema ainda pouco discutido no espaço acadêmico: os letramentos literários e a avaliação 
da literatura. Enquanto o ensino de línguas vem sendo objeto de inúmeros estudos e debates, engajados na crítica às perspectivas tidas como tradicionais e na proposição de novas estratégias didáticas para os eixos da linguagem, a "virada pragmática" no campo do ensino da literatura vem acontecendo a "passos de tartaruga".

Os estudos sobre o letramento no Brasil se iniciaram na segunda metade da década de 1980, quando a academia passou a se ocupar não só do processo de alfabetização, mas também das demandas sociais que envolvem a leitura e a escrita. Como afirma Soares (2001), novas palavras aparecem para atender às necessidades de nomear algum fenômeno emergente. No caso, as discussões sobre letramento surgiram nesse período, porque outro problema educacional emergia: o analfabetismo funcional, isto é, a precária condição dos sujeitos que, embora alfabetizados, não se apropriaram das práticas sociais que envolvem a leitura e a escrita, seja como hábito cultural, seja como tecnologia.

Nas palavras de Soares (2001, p. 72, grifos da autora), "letramento é o que as pessoas fazem com as habilidades de leitura e de escrita, em um contexto específico, e como essas habilidades se relacionam com as necessidades, valores e práticas sociais". O letramento, portanto, diz respeito às formas de comunicação e interação mediadas pela escrita, aos valores a ela atribuídos e aos conhecimentos construídos por meio dessa modalidade, aos modos como as pessoas a significam e significam o mundo, o que varia de acordo com o contexto sócio-histórico.

Em razão da heterogeneidade de práticas de letramento, Rojo (2009) advoga que a educação linguística, ancorada nos princípios da formação ética, do espírito democrático e do desenvolvimento da criticidade, deve optar por uma abordagem plural que contemple as diversas: materialidades discursivas (os gêneros do discurso que circulam em diferentes esferas sociais), semioses (a escrita junto com outras formas sígnicas - imagem, música, corpo, gesto, oralidade -, especialmente nas mídias digitais) e culturas (locais e globais; vernaculares e letradas; dominantes, valorizadas e populares marginalizadas; produtos da cultura de massa). Por isso, faz a opção pelo termo "letramentos múltiplos" (multissemióticos, multiculturais e críticos).

Dada a extensão dos "letramentos múltiplos", é possível identificá-los conforme as esferas discursivas em que eles se concretizam, em que a escrita produz sentido: midiática, científica, cotidiana, literária, por exemplo. A expressão "letramento literário" começou a ser utilizada no Brasil no fim da década de $1990^{1}$. 
Cosson (2009) argumenta que esse é um letramento diferente dos outros, porque a literatura pode "tornar o mundo compreensível transformando a sua materialidade em palavras de cores, odores, sabores e formas intensamente humanas" (COSSON, 2009, p. 17), além de se constituir em um modo especial de acessar a escrita, pois proporciona o contato com esse universo discursivo a partir do domínio das próprias palavras. Em outros termos, experimenta-se sensorialmente o mundo por meio da literatura, e é pela literatura que se adquire um saber sobre ela mesma².

Tomando a acepção de "letramento" como uso social que se faz da escrita (SOARES, 2001), podemos entender os letramentos literários, na perspectiva de Paulino e Cosson (2009, p. 67), como “[...] o processo de apropriação da literatura enquanto construção literária de sentidos", ou, conforme enfatizam Souza e Cosson (2011, p. 103), como "uma experiência de dar sentido ao mundo por meio de palavras que falam de palavras, transcendendo os limites de tempo e espaço".

Usamos o termo letramentos literários propositalmente no plural, por considerarmos que não se leem (ou se escrevem) os gêneros da mesma maneira, ainda que sejam da mesma esfera discursiva. Como afirma Magda Soares (2005, p. 30), a leitura "é um processo complexo e multifacetado: depende da natureza, do tipo, do gênero daquilo que se lê, e depende do objetivo que se tem ao ler". Em relação à literatura, vai-se além: depende ainda do estilo do autor, da estética, do distanciamento entre o contexto de produção da obra e as condições de circulação e recepção. Parafraseando a autora, não se assiste a um videopoema da mesma forma e com a mesma finalidade que se lê um folheto de cordel; não se lê um romance de Proust com os mesmos protocolos e objetivos com que se lê uma crônica no jornal; não se acessam as canções na internet como se leem os sermões de Vieira.

Neste trabalho, iremos investigar como tais práticas de letramentos literários são abordadas e, mais especificamente, qual lugar a literatura ocupou no âmbito do Exame Nacional do Ensino Médio (ENEM) 2013. O Ministério da Educação conferiu a esse exame, nos últimos anos, notória importância no cenário educacional, haja vista seus resultados serem usados para "compor a avaliação de medição da qualidade do Ensino Médio no País" (MEC/INEP, 2013, p. 2) e facultados para acesso ao Ensino Superior e/ou obtenção do certificado de conclusão do Ensino Médio.

Supõe-se, assim, que a matriz curricular do ENEM define as competências e as habilidades mínimas esperadas do aluno no 
fim da educação básica, as quais devem lhe oferecer as condições, como previsto pela Lei de Diretrizes e Bases da Educação Nacional (LDB), n.9.394/96, de continuação dos estudos ou de ingresso no mundo do trabalho. Por essas razões e outras, sobre as quais discorreremos no item a seguir, os conteúdos, as competências e as habilidades privilegiados pelo ENEM assumem um papel relevante na definição do espaço atribuído aos diversos saberes no currículo das escolas, entre eles, a literatura.

Diante desse quadro, postulamos como objetivos do nosso trabalho: a) analisar as questões da prova do ENEM $2013^{3}$ que envolvem a leitura de gêneros literários, a fim de averiguar a natureza do tratamento a eles oferecido; b) indicar o percentual de questões que envolvem essa área do conhecimento frente ao total da prova, a fim de se verificar a sua importância perante as demais áreas; c) identificar os gêneros, os autores e, a partir disso, os letramentos literários ${ }^{4}$ que são abordados na prova; e d) reconhecer $\mathrm{a}(\mathrm{s})$ concepção(ões) de leitura que subjaz(em) à prova. No tocante à prova de Redação e Linguagens, Códigos e Suas Tecnologias, também observamos o tratamento dado pelas questões à disciplina literatura. Quanto a isso, consideramos aqui que letrar literariamente o aluno é mediar a compreensão dos textos literários, assim como a aprendizagem de conhecimentos sobre as estéticas, a teoria e a crítica literária relevantes para a apreciação desses textos.

Nosso trabalho está estruturado em quatro partes: 1) sucinta apresentação do ENEM e de sua relevância, do seu perfil avaliativo e das concepções que revela acerca da literatura em sua matriz curricular; 2) breve exposição acerca do ensino de literatura e dos resultados de pesquisas sobre a sua avaliação em edições anteriores desse exame; 3) análise dos dados encontrados na prova de 2013, pautada pela reflexão sobre seus possíveis impactos nas escolas, em contraste com as expectativas que temos para a abordagem da literatura nos anos finais da educação básica.

Nas considerações finais, fazemos uma síntese dos resultados encontrados. Com base na análise da edição 2013 do exame e nas pesquisas acerca deoutras edições, consideramos queoENEManuncia para as escolas um ensino de literatura focado predominantemente na compreensão textual e nos recursos linguístico-estilísticos. Assim, não leva em conta sua dimensão literária, pois poucas questões avaliam de fato os letramentos literários, mobilizando o universo imaginário e simbólico da literatura ou os conhecimentos específicos sobre essa esfera cultural. 


\section{PERFIL DE AVALIAÇÃO DO ENEM}

Criado em 1998, o ENEM é uma prova anual, individual e não obrigatória que tem como objetivo avaliar alunos que estão finalizando ou já tenham finalizado o Ensino Médio e lhes oferecer dados para uma autoavaliação, tomando como referência a matriz curricular que fundamenta a sua elaboração.

Em 2009, o exame foi reformulado e também passou a ser utilizado como certificado de conclusão do Ensino Médio para alunos maiores de 18 anos e como forma de seleção ao Ensino Superior do país. Neste caso, a nota atingida no ENEM pode garantir ao aluno uma vaga em uma Instituição de Ensino Superior (IES) pública ou privada ou a obtenção de uma bolsa integral ou parcial do Programa Universidade para Todos (ProUni) em instituição privada. Tais possibilidades oferecidas pelo ENEM lhe conferem um papel de significativa magnitude e que vinha sendo desempenhado pelos tradicionais vestibulares nas últimas décadas: a influência sobre o currículo escolar.

Como se percebe, estes exames acabam provocando um processo de inversão pedagógica na educação brasileira: não é a prática de ensino quem direciona o que será avaliado, é a avaliação quem dita o que fará parte do currículo. Mais do que um reflexo, ela refrata o processo de ensino-aprendizagem e, a depender da escola, determina os conteúdos, as competências e as habilidades que serão privilegiados. Dantes, o programa dos vestibulares e, no âmbito da Literatura, a lista de obras direcionavam o que seria abordado nas escolas. Hoje, vários livros didáticos de língua portuguesa do Ensino Médio apresentam listas de questões das edições anteriores deste exame e, em seus anexos, a matriz curricular do ENEM, segundo constata o Guia dos Livros Didáticos de Língua Portuguesa 2012 (2011, p. 18):

Parte das coleções contempla, explicitamente, competências leitoras avaliadas por
exames vestibulares; e, em especial, por sistemas de avaliação de desempenho do
alunado como o ENEM. Há, inclusive, coleções em que a concepção de leitura do
Enem, e mesmo sua matriz de referência, são objeto de estudo sistemático - com
exposições teóricas a respeito, exemplos de testes dedicados a cada competência e
exercícios de identificação de qual competência está em foco num determinado item.

Pode-se dizer que a matriz do ENEM (MEC/INEP, 2013) constitui um avanço metodológico em relação aos programas dos vestibulares, uma vez que agrupa os saberes de forma interdisciplinar pelo campo do conhecimento, focando as competências e as habilidades tidas como basilares para a formação dos estudantes. 
No âmbito da área de Linguagens, Códigos e Suas Tecnologias, a proposta privilegia a compreensão textual, os usos das linguagens, a análise e a reflexão sobre os textos considerando o seu contexto, como se verifica no item que trata especificamente da literatura:

Competência de área 5 - Analisar, interpretar e aplicar recursos expressivos das linguagens, relacionando textos com seus contextos, mediante a natureza, função, organização, estrutura das manifestações, de acordo com as condições de produção e recepção.

H15 - Estabelecer relações entre o texto literário e o momento de sua produção, situando aspectos do contexto histórico, social e político.

H16 - Relacionar informações sobre concepções artísticas e procedimentos de construção do texto literário.

H17 - Reconhecer a presença de valores sociais e humanos atualizáveis e permanentes no patrimônio literário nacional. (MEC/INEP, 2013, p. 37)

A competência e as habilidades acima assinalam um modelo avaliativo diferente do dos exames vestibulares tradicionais focado na historiografia literária, pois não cobram a memorização de datas, períodos, nomes ou características dos movimentos literários, dos autores e das obras, nem mesmo objetivam uma análise do texto estereotipada, que apenas reproduz o discurso da crítica canônica. O problema deste tipo de análise é que ela toma o texto como modelo do estilo de época ou do estilo do autor e renega o caráter transgressor da literatura (PINHEIRO, 2006), conduzindo a uma leitura que negligencia a singularidade de cada obra ${ }^{5} \mathrm{e}$ as diversas facetas de um escritor ${ }^{6}$.

A matriz curricular apoia-se numa pespectiva de abordagem do texto literário que privilegia a avaliação do "saber a literatura", e não do "saber sobre a literatura" (CEREJA, 2005; BRASIL, 2006 - Orientações Curriculares para o Ensino Médio, doravante OCNEM-; ROUXEL, 2013). Pedem-se o diálogo entre o texto e suas condições de produção (H15), a análise da configuração formal (H16) em relação com o movimento a que se vincula e o reconhecimento do caráter humanizador da literatura (H17). O enfoque no estudo do texto literário, e não na historiografia também fica claro na indicação dos objetos de conhecimento:

Estudo do texto literário: relações entre produção literária e processo social, concepções artísticas, procedimentos de construção e recepção de textos - produção literária e processo social; processos de formação literária e de formação nacional; produção de textos literários, sua recepção e a constituição do patrimônio literário nacional; relações entre a dialética cosmopolitismo/ localismo e a produção literária nacional; elementos de continuidade e ruptura entre os diversos momentos da literatura brasileira; associações entre 
concepções artísticas e procedimentos de construção do texto literário em seus gêneros (épico/narrativo, lírico e dramático) e formas diversas; articulações entre os recursos expressivos e estruturais do texto literário e o processo social relacionado ao momento de sua produção; representação literária: natureza, função, organização e estrutura do texto literário; relações entre literatura, outras artes e outros saberes. (MEC/INEP, 2013, p. 14, grifos do texto)

A prova, como se pode notar, trabalha em uma perspectiva mais ampla de análise do texto literário, em constante diálogo com seu contexto de produção, com outros textos e linguagens artísticas. Assim, confere maior abertura às escolas na definição do currículo. Desde sua concepção inicial, o ENEM procura propor questões reflexivas que solicitam a compreensão leitora e relacionam o conhecimento a problemas concretos e ao cotidiano do aluno.

Diferencia-se, portanto, do modelo do vestibular, duramente criticado por seu foco na aprendizagem conteudista, na acumulação e na memorização de informações. É com base também na crítica à influência perniciosa do vestibular na educação que o Ministério da Educação defende o "Novo ENEM como instrumento de indução da reestruturação dos currículos do Ensino Médio" (BRASIL, 2009, p. 3), convidando as instituições federais de Ensino Superior a atuarem como

protagonistas no processo de repensar o Ensino Médio, discutindo a relação entre conteúdos exigidos para ingresso na educação superior e habilidades que seriam fundamentais, tanto para o desempenho acadêmico futuro, quanto para a formação humana. (BRASIL, 2009, p. 3)

O edital de 2013 informa que, entre outras finalidades, os resultados do ENEM seriam usados para "criar referência nacional para o aperfeiçoamento dos currículos do Ensino Médio", "desenvolver estudos e indicadores sobre a educação brasileira" e "subsidiar a implementação de políticas públicas" (MEC/INEP, 2013, p. 2). Desse modo, atribui-se ao ENEM a função de promover paulatinamente a mudança de princípios e de orientações curriculares e, consequentemente, de oferecer subsídios para a avaliação e de contribuir para a melhoria da qualidade da educação básica. Pelas razões elencadas, vemos que o ENEM se constitui em um indicador do que se faz nas aulas de literatura do Ensino Médio.

\section{ENSINO E AVALIAÇÃO DA LITERATURA}

Sabendo que a escola é a principal agência de letramento em nossa sociedade e que muitos estudantes (em especial, os das 
classes menos favorecidas) só entram em contato com os textos literários através dessa agência, nosso posicionamento é o de que tais textos devem ter primazia nas aulas de língua portuguesa. As demais disciplinas realizam a leitura e/ou a produção de gêneros discursivos de cunho informativo e científico, como resumos, verbetes enciclopédicos, textos didáticos e reportagens, mas raramente exploram os da esfera literária ${ }^{7}$.

Este é um domínio do qual o professor de português é o especialista, cabendo-lhe a responsabilidade de despertar o gosto, mediar a leitura e o contato do aluno com as obras. Por isso, interrogamo-nos: se os docentes de língua portuguesa se esquivarem desse papel, quem irá realizá-lo? Souza e Cosson (2011, p. 102) alertam que "o letramento literário precisa da escola para se concretizar, isto é, ele demanda um processo educativo específico que a mera prática de leitura de textos literários não consegue sozinha efetivar".

O espaço dado a esse eixo nem sempre foi objeto de discussão entre professores e pesquisadores, pelo contrário, a ideologia dominante, de fins do século XIX até meados dos anos 50 do século $\mathrm{XX}$, prezava a presença do letramento literário na educação em geral, inclusive linguística. Das antologias - crestomatias, florilégios ou seletas de textos - aos livros didáticos, predominavam excertos de narrações, fábulas e poemas em geral, tomados como modelos a serem imitados nos exercícios de composição ou a serem oralizados na prática de declamação e leitura em voz alta, ou ainda como base para a análise de estruturas linguísticas, de questões gramaticais e de vocabulário.

Tais textos serviam como pretexto para um ensino prescritivo da oralidade, da escrita e das regras gramaticais. Soares (2004) comenta que o caráter normativo da educação faz-se notar inclusive pela seleção textual que se orientava pelos critérios do pertencimento ao cânone, do uso culto da língua e da abordagem de conteúdos moralizantes, em detrimento da qualidade estética. Assim, a leitura literária tinha prioridade, contudo, era realizada para fins não literários.

Em meados das décadas de 1960 e 1970, a literatura começou a perder seu espaço para outros gêneros, como os quadrinhos, as propagandas e as matérias jornalísticas, em função do advento e do sucesso das teorias da comunicação e da informação (PIETRI, 2012; ROJO, 2009; SOARES, 2004).

Os textos, literários ou não, eram abordados pelo viés instrumental em atividades de leitura como decodificação, e a literatura, por sua vez, continuava ancorada nos pilares tradicionais, agora com enfoque nacionalista: prioridade dada aos clássicos brasileiros 
(e, por vezes, portugueses), como patrimônio coletivo, formação de cultura beletrista, fixação historiográfica e reprodução da crítica socialmente legitimada; tal era a pedagogia decorrente do contexto sociopolítico da ditadura militar. De acordo com Cereja (2005), o espírito tecnicista da época também corroborou com a fragmentação da disciplina português em gramática, redação e literatura, muitas vezes, com professores, materiais didáticos e avaliações específicos.

Ainda hoje a tripartição da disciplina no Ensino Médio reforça a dicotomia entre língua e literatura, como se esta não fosse uma forma de linguagem. As aulas e os materiais didáticos de literatura organizam-se do seguinte modo: exposição dos movimentos estéticos na linha do tempo, apresentação dos fatos históricos mais marcantes, das características das escolas literárias, seguidas dos principais autores e obras. Os exercícios, em geral, pedem que o aluno recupere tais conteúdos e os identifique na análise de poemas ou excertos das obras, desenvolvendo apenas as habilidades de reconhecimento e aplicação. Trata-se de uma "concepção 'culturalista' e transmissiva do ensino da literatura, isto é, uma concepção mais preocupada em transmitir aos alunos a cultura oficial do que construir esse conhecimento por meio do contato direto com os objetos culturais" (CEREJA, 2005, p. 43, grifos do autor).

O método dedutivo-expositivo exige uma visão de conjunto da história literária, mas induz a uma leitura objetiva e superficial das obras, o que pouco contribui para o exercício da liberdade, para a formação ética e do pensamento crítico e autônomo, como estabelece o inciso III da LDBEN n. 9.394/96, retomado pelas OCNEM (BRASIL, 2006) como finalidade do ensino da literatura. No bojo dessas críticas, elencamos alguns princípios que colaboram para a promoção e o desenvolvimento dos letramentos literários em sala de aula, pautados pelas OCNEM (BRASIL, 2006) e por diversos pesquisadores, entre os quais, Cosson (2009), Cereja (2005), Jouve (2012), Rangel (2005) e Rouxel (2013):

a) centralidade e integralidade dos textos literários, para que o aluno possa experienciá-los e defrontar-se com a sua singularidade;

b) abertura para as escolhas literárias dos alunos, considerando, porém, que a seleção das obras precisa contribuir para a sua formação estética, e não estar à revelia da busca pelo prazer imediato;

c) valorização da fruição estética como atividade que 
envolve o despertar de sentimentos e emoções a partir da compreensão/inteligibilidade do texto;

d) introdução de questões históricas e teóricas a partir dos textos;

e) trabalho com a metaleitura, pela qual o aluno aprenda a analisar e falar sobre a literatura;

f) dialogicidade entre textos antigos e modernos ou contemporâneos, priorizando no estudo da diacronia literária o que é relevante por seu significado e legado cultural para a sincronia;

g) promoção de leituras intersemióticas, isto é, do diálogo entre obras literárias e demais obras artísticas, sejam do mesmo período ou não;

h) oportunidade de produção de gêneros literários, visando a ampliar a competência lexical e comunicativa dos alunos, a partir da apropriação dos modos de dizer e de recursos expressivos dessa esfera;

i) contribuição da literatura para a construção da identidade linguística e nacional;

j) adoção de uma concepção extensiva de literatura, aberta à diversidade e à heterogeneidade de obras, autores, estilos e gêneros; mas que também leve em conta a

k) distinção entre valor cultural e valor estético, afinal, ainda que algumas produções sejam de cabal importância para a cultura, como o rap, não possuem a mesma configuração estética que os poemas de Fernando Pessoa, por exemplo.

Esses, contudo, não parecem efetivamente ser os princípios que pautam a elaboração das questões das provas do ENEM, nem mesmo aqueles preconizados em sua matriz curricular (cf. item 1), conforme atestam os estudos de Andrade (2011), Fischer et al. (2012) e Medeiros (2012).

Fischer et al. (2012) investigaram as questões de literatura nas provas do ENEM de 1998 a $2010^{8}$, tendo chegado à conclusão de que o exame vem instaurando um modelo de avaliação nada promissor, pois as questões, majoritariamente (cerca de $80 \%$ ), prescindem do conhecimento específico sobre a literatura e ocupam, em média, apenas $13 \%$ do total da prova. Em 2010, este índice caiu pela metade $(6,1 \%)$, e $92 \%$ das questões dispensavam o aluno de ter assistido a qualquer aula de literatura. Mais lastimáveis são os resultados 
encontrados sobre as provas de 2000, 2005 e 2011, em que nenhuma questão exigiu do aluno algum conhecimento literário?.

Outro dado relevante da pesquisa é a presença quase absoluta do cânone como critério de seleção textual: Drummond é o autor mais citado, seguido por Machado de Assis e Manuel Bandeira. Fora do cânone literário, são encontrados apenas os autores de quadrinhos ${ }^{10}$, mais citados, inclusive, que escritores tradicionalmente lidos na escola, como Álvares de Azevedo. Tal dado causa certo estranhamento, uma vez que os gêneros quadrinizados não são constitutivos da esfera literária propriamente dita; eles pertencem a outros domínios da criatividade humana - o humor e o entretenimento. Desse modo, concluímos, com base nos dados desta pesquisa, que não há no ENEM representação da literatura para além da lista de escritores consagrados.

Eble (2013) credita esse fato à retroalimentação que ocorre entre as universidades e o ENEM, ambos norteados, de acordo com a autora, pela perspectiva historiográfica que ainda prevalece nos cursos de Letras. Cruzando os dados da pesquisa de Fischer et al. (2012) com um levantamento dos escritores mais citados pelos pesquisadores no Currículo Lattes, Eble (2013) mostra que os mesmos escritores que são objeto de pesquisa dos profissionais nas universidades acabam figurando nas provas do ENEM; assim, como a maior parte dos elaboradores dos itens das provas é de docentes dessas instituições, tal coincidência não é mero acaso.

A diversidade de gêneros literários também é pouco contemplada, predominando a lírica (poemas e canções) frente às narrativas (fragmentos de contos, crônicas e romances), possivelmente pelas delimitações de espaço da prova. Fischer et al. (2012) constataram que as Histórias em Quadrinhos (HQs) sozinhas são o segundo gênero mais presente nas provas, perdendo apenas para a poesia, enquanto não há quaisquer exemplares de peças teatrais, que são, de fato, textos literários.

Andrade (2011) investiga as implicações que o ENEM traz para a escola no tocante ao ensino da literatura a partir de análise das provas de 1999 a 2009. Ela constata, a partir de exemplos de provas anteriores a 2008, que os textos literários, inclusive os consagrados, servem de base para avaliar se o aluno é capaz de analisar os elementos linguísticos, de inferir os recursos expressivos e de compreender relações semânticas, entre outros aspectos que independem da natureza discursiva do texto.

Quanto às provas mais recentes, os exemplos analisados por Andrade (2011) indicam uma visão historicista e evolutiva da literatura, 
segundo a qual um estilo literário sempre nega o que o antecedeu. Mesmo algumas questões que exigem conhecimentos específicos dispensam a leitura do texto, pois basta o aluno conhecer o movimento literário a ele relacionado para que consiga respondê-las. A autora chega à conclusão de que o ENEM mantém uma abordagem tradicional, ora voltada para a interpretação dos recursos estilísticos, ora para o reconhecimento das características das estéticas literárias, ora para o uso desses textos como pretexto para a abordagem de conteúdos linguísticos que poderiam tomar qualquer outra unidade para esse fim.

Medeiros (2012), em pesquisa acerca da prova do ENEM de 2011, alerta para o reduzido número de questões de literatura dessa edição: apenas sete ou oito, a depender da perspectiva, no total de $45 \mathrm{da}$ área de Linguagens, Códigos e Suas Tecnologias. Se bem que, segundo a autora, tenha havido alguns avanços em comparação com a prova de 2009 - tais quais a clareza dos enunciados e a redução de questões a serviço do estudo da língua ou da estilística -, a prova de 2011 realiza uma abordagem de temas sociopolíticos a partir da leitura literária, abordagem esta que poderia ser realizada a partir de qualquer outro texto.

Considerando as provas de 2009 e 2011, Medeiros (2012, p. 13) fez constatação similar às das outras pesquisas: "os textos são abordados na vertente da linguagem, e não da cultura veiculada por intermédio da literatura". Desse modo, eles servem como pretexto para perspectivas de outras áreas, quer seja a língua, quer sejam as humanidades. Para a autora, "a prova, no formato em que é realizada, pode resultar em péssima influência para o ensino de literatura, sobretudo porque não a considera em sua especificidade." (MEDEIROS, 2012, p. 1).

Em suma, essas pesquisas revelam que a maioria das questões "supostamente" de literatura versa sobre aspectos da língua portuguesa e/ou exige um trabalho de compreensão textual à revelia das condições de produção e, principalmente, do contexto líterocultural que envolve a obra.

\section{A PROVA DO ENEM 2013}

Com o propósito de investigar os caminhos teóricometodológicos indicados pelo ENEM 2013 para a abordagem dos letramentos literários na escola, tomamos para análise tanto as questões de literatura scrito sensu (história da literatura, estilística, análise e interpretação do texto literário) como as que a relacionam a outros campos do conhecimento, como a linguística, as artes, as ciências e as humanidades. 
O nosso corpusé constituído, portanto, pelas questões que solicitam a leitura de textos literários e/ou versam sobre algum conhecimento literário específico. Entendemos por leitura literária a que envolve os gêneros tradicionalmente associados a essa esfera, como o conto, a crônica, o romance e o poema, mas também gêneros correlacionados ${ }^{11}$, como a letra de canção ${ }^{12}$, o texto didático e o ensaio crítico $^{13}$.

$\mathrm{Na}$ edição de 2013 do $\mathrm{ENEM}^{14}$, das 180 questões que compõem o total da prova, apenas 21 tomaram por objeto um texto literário, perfazendo um índice próximo ao encontrado por Fischer et al. (2012): 11,67\%. Embora a presença da literatura pareça pouco significativa em relação às outras disciplinas que formam o conjunto do exame, foi razoável seu percentual de questões na prova de Linguagens, Códigos e Suas Tecnologias $(31,11 \%)$, considerando-se a variedade de disciplinas e objetos de conhecimento que essa área contempla. Isso fica claro na tabela a seguir:

TABELA 1 - Abordagem da literatura por área do conhecimento

\begin{tabular}{lllll}
\hline $\begin{array}{l}\text { Provas por áreal } \\
\text { Questões que } \\
\text { envolvem } \\
\text { literatura }\end{array}$ & $\begin{array}{l}\text { Linguagens, } \\
\text { Códigos e Suas } \\
\text { Tecnologias }\end{array}$ & $\begin{array}{l}\text { Ciências Humanas } \\
\text { e Suas Tecnologias }\end{array}$ & $\begin{array}{l}\text { Ciências da } \\
\text { Natureza e Suas } \\
\text { Tecnologias }\end{array}$ & $\begin{array}{l}\text { Matemática e Suas } \\
\text { Tecnologias }\end{array}$ \\
\hline Total & 14 & 6 & 1 & - \\
\hline Percentual & $31,11 \%$ & $13,33 \%$ & $2,2 \%$ & - \\
\hline
\end{tabular}

Fonte: Elaborado pelos autores deste artigo.

Nessa edição, a maior parte das questões que envolve literatura a abordou de forma isolada ou a vinculou à língua portuguesa, como tradicionalmente se faz nas escolas. Diferenciaram-se desse perfil duas questões de Língua Estrangeira Moderna (LEM) que trouxeram textos literários em espanhol, favorecendo o contato do aluno não só com a língua, mas também com a cultura hispânica. No entanto, tais questões avaliaram a compreensão do texto apenas, prescindindo de conhecimento literário, como se pode observar no enunciado da questão 95, que requer uma inferência global:

\section{Duerme negrito}

Duerme, duerme, negrito, que tu mamá está en el campo, negrito...

Te va a traer 
codornices para ti.

Te va a traer

rica fruta para ti.

Te va a traer

carne de cerdo para ti.

Te va a traer

muchas cosas para ti [...]

Duerme, duerme, negrito

que tu mamá está en el campo,

negrito...

Trabajando, trabajando duramente, trabajando sí.

Trabajando y no le pagan,

trabajando sí.

Disponível em: http://letras.mus.br. Acesso em: 26 jun. 2012 (fragmento)

Duerme negrito é uma cantiga de ninar da cultura popular hispânica, cuja letra problematiza uma questão social, ao

destacar o orgulho da mulher como provedora do lar. evidenciar a ausência afetiva da mãe na criação do filho. retratar a precariedade das relações de trabalho no campo. ressaltar a inserção da mulher no mercado de trabalho rural. exaltar liricamente a voz materna na formação cidadã do filho.

(INEP/MEC, 2013b, p. 6)

As questões de inglês, contudo, não estabelecem relação entre o idioma e a literatura. Também as questões de artes, educação física e informática não fazem quaisquer vínculos com essa esfera, embora haja objetos de saber comuns entre elas: na informática, gêneros literários emergentes, como o microconto e o videopoema; nas artes, o diálogo entre as escolas literárias e as manifestações artísticas de seu tempo. A ausência de questões que relacionem essas disciplinas é um reflexo da organização da matriz curricular, que, apesar de uni-las em um campo, separa as competências e os objetos de conhecimento pelos saberes disciplinares.

A área de humanidades, por sua vez, faz algum uso dos textos literários (13,33\% em relação ao total de questões) para abordar seus objetos de conhecimento, na tentativa de estabelecer um elo entre as obras e os aspectos geográficos que ela evoca ou o contexto sociopolítico de sua produção. Algumas questões prescindem dos conteúdos da área e limitam-se à compreensão dos aspectos temáticos do texto, tal qual o enunciado 30, baseado em trecho da carta de Caminha: "[...] A carta de Pero Vaz de Caminha permite entender o projeto colonizador para a nova terra. Nesse trecho, o relato enfatiza o seguinte objetivo: [...]" (INEP/MEC, 2013b, p. 2). 
Em outras, o texto funciona como pretexto a partir do qual se cobram saberes históricos ou científicos. Exemplo disso é a questão 4, que recupera um famoso trecho da obra Os sertões (Parte A: Terra):

4. Então, a travessia das veredas sertanejas é mais exaustiva que a de uma estepe nua. Nesta, ao menos, o viajante tem o desafogo de um horizonte largo e a perspectiva das planuras francas. Ao passo que outra o afoga; abrevia-lhe o olhar; agride-o e estonteia-o; enlaça-o na trama espinescente e não o atrai; repulsa-o com as folhas urticantes, com o espinho, com os gravetos estalados em lanças, e desdobra-se-lhe na frente léguas e léguas, imutável no aspecto desolado; árvore sem folhas, de galhos estorcidos e secos, revoltos, entrecruzados, apontando rijamente no espaço ou estirando-se flexuosos pelo solo, lembrando um bracejar imenso, de tortura, da flora agonizante...

Cunha, E. Os sertões. Disponível em: <http://pt.scribd.com>. Acesso em: 2 jun. 2012.

Os elementos da paisagem descritos no texto correspondem a aspectos biogeográficos presentes na composição de vegetação xerófila. formação de florestas latifoliadas. transição para mata de grande porte. adaptação à elevada salinidade.

homogeneização da cobertura perenifólia.

(INEP/MEC, 2013b, p. 2)

A leveza de estilo com que Euclides narra a estepe contrasta com o longo período em que retrata as veredas. A disposição de termos, expressões e orações coordenadas de forma gradativa permite-nos experienciar a sensação de cansaço do homem sertanejo desbravando a caatinga. Entretanto, tais efeitos de sentido não são analisados. Diferentemente da questão de espanhol citada, que, ao menos, explora a compreensão textual em LEM, exigindo a inferência da ideia global, esta não trata nem de um saber da literatura, nem sobre a literatura. Mesmo sem compreender o texto, o aluno pode julgar as alternativas se tiver conhecimentos mínimos sobre o sertão ("d", pelo tipo de solo, e "b" e "c", pela vegetação) e domínio da nomenclatura técnica (xerófila em "a" e perenifólia em "e"). A narração funciona como um quadro que ilustra o espaço no qual o aluno irá buscar algumas informações relativas à vegetação.

Quanto à matemática e às demais ciências, a prova não estabelece qualquer conexão com a leitura literária, salvo a seguinte questão: 
78. Eu também podia decompor a água, se fosse salgada ou acidulada, usando a pilha de Daniell como fonte de força. Lembro o prazer extraordinário que sentia ao decompor um pouco de água em uma taça para ovos quentes, vendo-a separar-se em seus elementos, o oxigênio em um eletrodo, o hidrogênio no outro. A eletricidade de uma pilha de 1 volt parecia tão fraca, e no entanto podia ser suficiente para desfazer um composto químico, a água...

SACKS, O. Tio Tungstênio: memórias de uma infância química. São Paulo: Cia. das Letras, 2002.

O fragmento do romance de Oliver Sacks relata a separação dos elementos que compõem a água. O princípio do método apresentado é utilizado industrialmente na

A) obtenção de ouro a partir de pepitas.

B) obtenção de calcário a partir de rochas.

C) obtenção de alumínio a partir da bauxita.

D) obtenção de ferro a partir de seus óxidos.

E) obtenção de amônia a partir de hidrogênio e nitrogênio.

(INEP/MEC, 2013b, p. 28)

Assim como as questões de Ciências Humanas e Suas Tecnologias, esta não propõe um diálogo efetivo entre literatura e química. O trecho das memórias serve apenas para evocar o método de separação de elementos químicos. Nota-se que a questão toma o texto literário como fator de contextualização, no entanto, qualquer outro gênero científico ou informativo poderia realizar esse papel. A linguagem afetiva, o envolvimento e o entusiasmo do narrador-personagem, em contraste com a objetividade dos procedimentos descritos, não são tematizados. O pouco cuidado com a literariedade faz-se notar na nomeação equivocada do gênero como "romance", quando o próprio subtítulo do livro já o classifica enquanto "memórias".

O princípio da interdisciplinaridade, tão defendido pelas diretrizes oficiais do ENEM (INEP, 2005), portanto, não se concretiza efetivamente na edição de 2013 no que concerne à relação entre a literatura e as demais áreas. Estas realizam uma avaliação de seus objetos de estudo por meio dos textos literários, que ilustram conceitos ou fenômenos a serem cobrados dos alunos.

Analisando as 21 questões que envolvem a literatura, obtivemos outros resultados. Entre os gêneros literários, a lírica (poemas e canções) ocupa a maior parte da prova (cerca de 61,54\%), e o poema é o gênero mais recorrente (oito ocorrências no total). A distribuição de gêneros literários por prova pode ser verificada na Tabela 2: 
TABELA 2 - Gêneros literários

\begin{tabular}{|c|c|c|c|c|c|c|}
\hline \multicolumn{3}{|c|}{$\begin{array}{l}\text { Provas por áreal } \\
\text { Gêneros literários }\end{array}$} & $\begin{array}{l}\text { Linguagens, } \\
\text { Códigos } \\
\text { e Suas } \\
\text { Tecnologias }\end{array}$ & $\begin{array}{l}\text { Ciências } \\
\text { Humanas } \\
\text { e Suas } \\
\text { Tecnologias }\end{array}$ & $\begin{array}{l}\text { Ciências da } \\
\text { Natureza } \\
\text { e Suas } \\
\text { Tecnologias }\end{array}$ & $\begin{array}{l}\text { Matemática } \\
\text { e Suas } \\
\text { Tecnologias }\end{array}$ \\
\hline \multirow[t]{5}{*}{ Lírica } & \multicolumn{3}{|l|}{ Poema visual } & 1 & & \\
\hline & \multicolumn{2}{|l|}{ Poema } & 6 & 1 & & \\
\hline & \multirow[t]{3}{*}{ Canção } & $\begin{array}{l}\text { Trechos de } \\
\text { canção }\end{array}$ & 5 & 1 & & \\
\hline & & $\begin{array}{l}\text { Rap } \\
\text { (trecho) }\end{array}$ & 1 & & & \\
\hline & & $\begin{array}{l}\text { Cantiga de } \\
\text { ninar }\end{array}$ & 1 & & & \\
\hline \multirow[t]{6}{*}{ Prosa } & \multicolumn{2}{|l|}{$\begin{array}{l}\text { Romance }^{15} \\
\text { (trecho) }\end{array}$} & 2 & 1 & & \\
\hline & \multicolumn{2}{|l|}{$\begin{array}{l}\text { Memória } \\
\text { (trecho) }\end{array}$} & & 1 & 1 & \\
\hline & \multicolumn{2}{|l|}{$\begin{array}{l}\text { Carta }^{16} \\
\text { (trecho) }\end{array}$} & 1 & 1 & & \\
\hline & \multicolumn{2}{|l|}{$\begin{array}{l}\text { Peça teatral } \\
\text { (trecho) }\end{array}$} & 1 & & & \\
\hline & \multicolumn{2}{|l|}{ Crítica } & 1 & & & \\
\hline & \multicolumn{2}{|l|}{$\begin{array}{l}\text { Texto } \\
\text { didático } \\
\text { (trecho) }\end{array}$} & 1 & & & \\
\hline
\end{tabular}

Fonte: Elaborado pelos autores deste artigo.

Os gêneros em prosa são mais diversificados e mais bemdistribuídos de forma equitativa, no entanto, a maioria é de fragmentos, possivelmente devido às configurações espaciais do exame e aos protocolos de leitura por ele exigidos. Tal fragmentação não dificulta, em geral, o processo de compreensão leitora, pois os textos possuem unidade de sentido.

Apesar da escassez de text os regionais e/ou populares e da ausência de narrativas de curta extensão (contos e crônicas), a seleção textual é mais representativa da produção literária que a das provas anteriores, consoante os resultados divulgados por Andrade (2011), Fischer et al. (2012) e Medeiros (2012), pois inclui um exemplar de texto dramático e contempla a variedade de estilos de um gênero ou 
subgêneros (poema e poesia visual; rap, canção e cantiga de ninar; diferentes composições narrativas e documentais).

Quanto aos autores e aos movimentos literários, observou-se umapresençasignificativadeescritoresecompositorescontemporâneos, perpassando vários estilos (e, inclusive, nacionalidades) que recobrem, de certo modo, a diversidade da produção artística atual. Não houve recorrência de autores, salvo Caminha, cujos escritos são estudados tanto pelas humanidades quanto pelas Letras. A Tabela 3 traz a relação das estéticas e dos escritores por prova:

TABELA 3 - Autores e movimentos literários

\begin{tabular}{|c|c|c|c|c|c|}
\hline \multicolumn{2}{|c|}{$\begin{array}{l}\text { Questões por áreal } \\
\text { Movimentos literários e autores }\end{array}$} & \multirow{2}{*}{$\begin{array}{l}\text { Linguagens, } \\
\text { Códigos } \\
\text { e Suas } \\
\text { Tecnologias } \\
\qquad 1\end{array}$} & \multirow{2}{*}{$\begin{array}{l}\text { Ciências } \\
\text { Humanas } \\
\text { e Suas } \\
\text { Tecnologias } \\
\qquad 1\end{array}$} & \multirow{2}{*}{$\begin{array}{l}\text { Ciências da } \\
\text { Natureza } \\
\text { e Suas } \\
\text { Tecnologias }\end{array}$} & \multirow{2}{*}{$\begin{array}{l}\text { Matemática } \\
\text { e Suas } \\
\text { Tecnologias }\end{array}$} \\
\hline Quinhentismo & Pero Vaz de Caminha & & & & \\
\hline $\begin{array}{l}\text { Romantismo } \\
\text { (prosa) }\end{array}$ & $\begin{array}{l}\text { Joaquim Manuel de } \\
\text { Macedo }\end{array}$ & & 1 & & \\
\hline Realismo & Machado de Assis & 1 & & & \\
\hline Parnasianismo & Raimundo Correia & 1 & & & \\
\hline Pré-Modernismo & Euclides da Cunha & & 1 & & \\
\hline \multirow[t]{3}{*}{ Modernismo } & $\begin{array}{l}\text { Oswald de Andrade } \\
\text { (primeira geração) }\end{array}$ & 1 & & & \\
\hline & $\begin{array}{l}\text { Jorge de Lima (segunda } \\
\text { geração) }\end{array}$ & 1 & & & \\
\hline & $\begin{array}{l}\text { Clarice Lispector } \\
\text { (terceira geração) }\end{array}$ & 1 & & & \\
\hline \multirow[t]{5}{*}{$\begin{array}{l}\text { Literatura } \\
\text { Contemporânea }\end{array}$} & $\begin{array}{l}\text { Concretismo (sem } \\
\text { autoria) }\end{array}$ & & 1 & & \\
\hline & Adélia Prado (poesia) & 1 & & & \\
\hline & Plínio Marcos (teatro) & 1 & & & \\
\hline & Gabriel, o pensador (rap) & 1 & & & \\
\hline & $\begin{array}{l}\text { Arnaldo Antunes } \\
\text { (canção) }\end{array}$ & & 1 & & \\
\hline
\end{tabular}


TABELA 3 - Autores e movimentos literários (continuação).

\begin{tabular}{|c|c|c|c|c|c|}
\hline \multicolumn{2}{|c|}{$\begin{array}{l}\text { Questöes por áreal } \\
\text { Movimentos literários e autores }\end{array}$} & \multirow{2}{*}{$\begin{array}{l}\text { Linguagens, } \\
\text { Códigos } \\
\text { e Suas } \\
\text { Tecnologias } \\
\qquad 1\end{array}$} & \multirow{2}{*}{$\begin{array}{l}\text { Ciências } \\
\text { Humanas } \\
\text { e Suas } \\
\text { Tecnologias }\end{array}$} & \multirow{2}{*}{$\begin{array}{l}\text { Ciências da } \\
\text { Natureza } \\
\text { e Suas } \\
\text { Tecnologias }\end{array}$} & \multirow{2}{*}{$\begin{array}{l}\text { Matemática } \\
\text { e Suas } \\
\text { Tecnologias }\end{array}$} \\
\hline $\begin{array}{l}\text { Literatura } \\
\text { Contemporânea }\end{array}$ & J. R. Tinhorão (ensaio) & & & & \\
\hline & A. Lasevicius (ensaio) & 1 & & & \\
\hline & $\begin{array}{l}\text { Nuno Júdice (poesia } \\
\text { portuguesa) }\end{array}$ & 1 & & & \\
\hline & $\begin{array}{l}\text { Gloria Fuertes } \\
\text { (poesia hispânica) }\end{array}$ & 1 & & & \\
\hline & $\begin{array}{l}\text { Olivier Sacks (químico } \\
\text { escritor) }\end{array}$ & & & 1 & \\
\hline & $\begin{array}{l}\text { Noel Rosa e João de } \\
\text { Barros (marcha-rancho) }\end{array}$ & 1 & & & \\
\hline & Dolores Duran (bolero) & 1 & & & \\
\hline & $\begin{array}{l}\text { Ary Barroso e Lamartine } \\
\text { Barro (samba-canção) }\end{array}$ & 1 & & & \\
\hline & Rita Lee (tropicalismo) & 1 & & & \\
\hline & $\begin{array}{l}\text { Tom Jobim e Vinicius de } \\
\text { Moraes (bossa nova) }\end{array}$ & 1 & & & \\
\hline \multirow[t]{2}{*}{ Populares } & Poema asteca & & 1 & & \\
\hline & $\begin{array}{l}\text { Cantiga de ninar } \\
\text { hispânica }\end{array}$ & 1 & & & \\
\hline
\end{tabular}

Fonte: Elaborado pelos autores deste artigo.

Vale salientar a majoritária representação de escritores (e compositores) pertencentes ao cânone artístico-literário nacional, valorizados socialmente pelas instâncias que controlam a produção e a circulação dos bens culturais, como a escola, o Estado, a mídia e, nesse caso específico, as editoras e a Academia Brasileira de Letras (ABL). O ENEM 2013 ratifica a ideia de que os letramentos a serem privilegiados na escola são os dominantes, em detrimento das práticas marginalizadas ou de resistência. Mesmo quando os escritos rompem com o beletrismo, com o uso culto atrelado às normas gramaticais, o foco recai nos aspectos temáticos ou nos recursos expressivos da língua, como na questão $106^{17}$ : 
Até quando?

Não adianta olhar pro céu

Com muita fé e pouca luta

Levanta aí que você tem muito protesto pra fazer

E muita greve, você pode, você deve, pode crer

Não adianta olhar pro chão

Virar a cara pra não ver

Se liga aí que te botaram numa cruz e só porque Jesus

Sofreu não quer dizer que você tenha que sofrer!

GABRIEL, O PENSADOR. Seja você mesmo (mas não seja sempre o mesmo). Rio de Janeiro: Sony Music, 2001 (fragmento).

As escolhas linguísticas feitas pelo autor conferem ao texto

A) caráter atual, pelo uso de linguagem própria da internet.

B) cunho apelativo, pela predominância de imagens metafóricas.

C) tom de diálogo, pela recorrência de gírias.

D) espontaneidade, pelo uso da linguagem coloquial.

E) originalidade, pela concisão da linguagem.

(INEP/MEC, 2013a, p. 9)

Embora a resposta $\mathrm{D}$ seja a correta, a questão não trata a linguagem coloquial como marca de transgressão dos letramentos literários dominantes. Ela avalia meramente a capacidade de o aluno reconhecer variações estilísticas da língua - internetês, linguagem metafórica, uso de gírias, registro coloquial -, as quais poderiam ser observadas em quaisquer outros gêneros que materializam diversas formas de expressão.

Em suma, os letramentos locais e vernaculares aparecem de forma diluída no exame: afora os exemplo das questões 98 e 106 citados, só se encontram dois textos experimentais (canção de Arnaldo Antunes e poema visual) e dois gêneros da literatura popular (poema asteca e cantiga de ninar). Além de ser ínfima a presença de autores e obras não canônicos, as questões propostas não exploram as estratégias discursivas, as características estéticas e os posicionamentos ideológicos que assinalam a quebra dos paradigmas dominantes.

Um último dado indicado pela Tabela 3 é a abrangência dos principais movimentos literários ocorridos no Brasil. Tal dado, todavia, não implica a abordagem dessas estéticas, inclusive nas questões referentes à área de linguagens, tal qual a $99^{18}$ :

\section{Mal secreto}

Se a cólera que espuma, a dor que mora

N'alma, e destrói cada ilusão que nasce, 
Tudo o que punge, tudo o que devora

O coração, no rosto se estampasse;

Se se pudesse, o espírito que chora,

Ver através da máscara da face,

Quanta gente, talvez, que inveja agora

Nos causa, então piedade nos causasse!

Quanta gente que ri, talvez, consigo

Guarda um atroz, recôndito inimigo,

Como invisível chaga cancerosa!

Quanta gente que ri, talvez existe,

Cuja ventura única consiste

Em parecer aos outros venturosa!

CORREIA, R. In: PATRIOTA, M. Para compreender Raimundo Correia.

Brasília: Alhambra, 1995.

Coerente com a proposta parnasiana de cuidado formal e racionalidade na condução temática, o soneto de Raimundo Correia reflete sobre a forma como as emoções do indivíduo são julgadas em sociedade. Na concepção do eu lírico, esse julgamento revela que

A) a necessidade de ser socialmente aceito leva o indivíduo a agir de forma dissimulada.

B) o sofrimento íntimo torna-se mais ameno quando compartilhado por um grupo social.

C) a capacidade de perdoar e aceitar as diferenças neutraliza o sentimento de inveja.

D) o instinto de solidariedade conduz o indivíduo a apiedar-se do próximo.

E) a transfiguração da angústia em alegria é um artifício nocivo ao convívio social.

(INEP/MEC, 2013a, p. 7)

A resolução dessa questão dispensa o estudante de refletir sobre o parnasianismo ou sobre a poética de Raimundo Correia ou até sobre as relações de aproximação/distanciamento entre o autor e a escola literária a que a crítica o vincula. Ainda que o enunciado articule o projeto estético do movimento parnasiano ao conteúdo temático do poema, basta que o aluno compreenda o posicionamento discursivo do eu lírico para responder à questão. Trata-se, portanto, de uma avaliação da compreensão leitora e, mais especificamente, da identificação do ponto de vista enunciativo, que poderia tomar por base qualquer outro texto.

Apesar desse quadro e das análises das provas anteriores relatadas no item 3, algumas questões do ENEM 2013 sinalizam para uma mudança de perspectiva da prova, pois exploram de fato os letramentos literários, exigindo observação e análise das particularidades dos gêneros literários e conhecimentos específicos sobre essa esfera cultural. A questão seguinte ilustra essa forma de avaliação: 


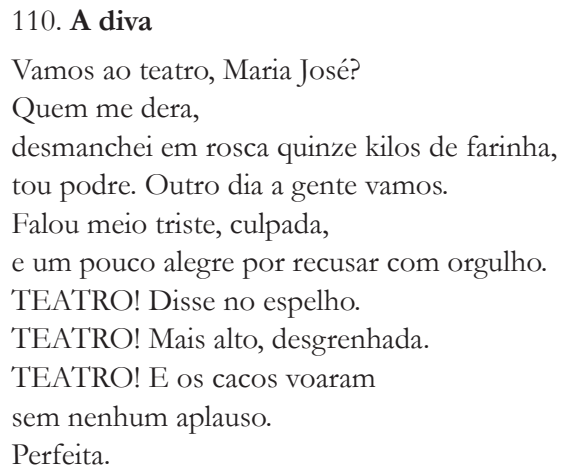

PRADO, A. Oráculos de maio. São Paulo: Siciliano, 1999.

Os diferentes gêneros textuais desempenham funções sociais diversas, reconhecidas pelo leitor com base em suas características específicas, bem como na situação comunicativa em que ele é produzido. Assim, o texto $A$ diva
A) narra um fato real vivido por Maria José.
B) surpreende o leitor pelo seu efeito poético.
C) relata uma experiência teatral profissional.
D) descreve uma ação típica de uma mulher sonhadora.
E) defende um ponto de vista relativo ao exercício teatral.

(INEP/MEC, 2013a, p. 10)

Esta questão explora a inovação formal da poesia de Adélia Prado e o estranhamento que ela promove. O enunciado indica as condições de produção a partir das quais o estudante deve avaliar o gênero, ou melhor, o propósito comunicativo que é realizado no texto $A$ diva. Para tal, ele deve produzir inferências locais (a ironia no título e no último verso, a metonímia em "cacos voaram", a entonação indicada tipograficamente) e analisar alguns recursos expressivos (a ausência de travessões para introduzir as falas do diálogo e a figuratividade linguística ${ }^{19}$ ) que o ajudem a recuperar o efeito de surpresa do poema.

A questão pressupõe que o estudante possua algum conhecimento sobre literatura contemporânea ou experimentalismo, a fim de identificar esse texto como exemplar do gênero poema em prosa, apesar dos elementos que o aproximam da narrativa e do drama (construção dialogal, personagens, voz do eu lírico simulando os comentários apreciativos de um narrador, solilóquio).

O aluno também precisa manejar seu saber sobre teoria literária para reconhecer o princípio da verossimilhança (e não confundir ficção com a narração de um "fato real" ou o relato de "uma experiência profissional", como dito nas alternativas "a" e "c", respectivamente) e a função estética dos textos poéticos (que não se confunde com 
o caráter utilitário de textos descritivos e argumentativos, tal qual se apresenta nas alternativas "d" e "e").

O ENEM 2013 promove também o letramento intersemiótico, ao estabelecer uma analogia entre um fragmento da carta de Caminha e uma tela de Portinari. No que tange a essa questão, a prova filia-se a uma perspectiva culturalista e não linear da historicidade, que concebe dialogismo entre a obra literária e outras produções literárias e artísticas, sejam do mesmo período histórico, sejam de outras épocas.

97.

\section{TEXTO I}

Andaram na praia, quando saímos, oito ou dez deles; e daí a pouco começaram a vir mais. E parece-me que viriam, este dia, à praia, quatrocentos ou quatrocentos e cinquenta. Alguns deles traziam arcos e flechas, que todos trocaram por carapuças ou por qualquer coisa que lhes davam. [...] Andavam todos tão bem-dispostos, tão bem feitos e galantes com suas tinturas que muito agradavam.

CASTRO, S. A carta de Pero Vaz de Caminha. Porto Alegre: L\&PM, 1996

\section{TEXTO II}

(fragmento).

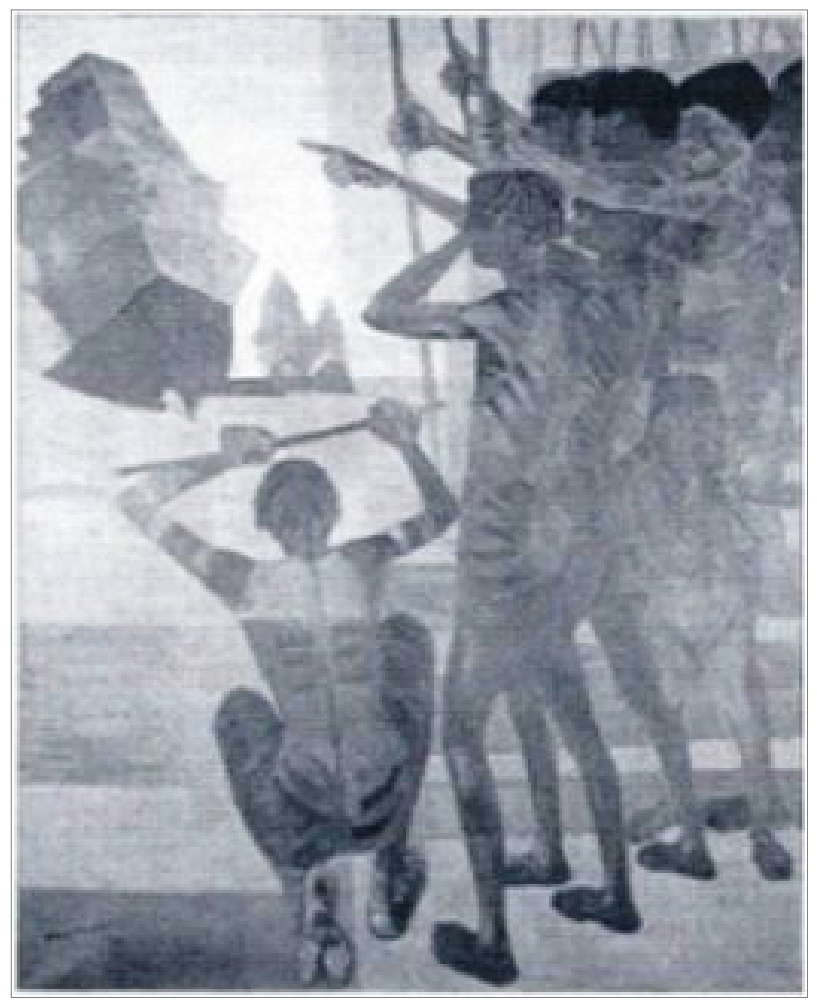

PORTINARI, C. O descobrimento do Brasil. 1956. Óleo sobre tela, $199 \times 169 \mathrm{~cm}$ Disponível em: www.portinari.org.br. Acesso em: 12 jun. 2013. 
Pertencentes ao patrimônio cultural brasileiro, a carta de Pero Vaz de Caminha e a obra de Portinari retratam a chegada dos portugueses ao Brasil. Da leitura dos textos, constata-se que

A) a carta de Pero Vaz de Caminha representa uma das primeiras manifestações artísticas dos portugueses em terras brasileiras e preocupa-se apenas com a estética literária.

B) a tela de Portinari retrata indígenas nus com corpos pintados, cuja grande significação é a afirmação da arte acadêmica brasileira e a contestação de uma linguagem moderna.

C) a carta, como testemunho histórico-político, mostra o olhar do colonizador sobre a gente da terra, e a pintura destaca, em primeiro plano, a inquietação dos nativos.

D) as duas produções, embora usem linguagens diferentes - verbal e não verbal -, cumprem a mesma função social e artística.

E) a pintura e a carta de Caminha são manifestações de grupos étnicos diferentes, produzidas em um mesmo momento histórico, retratando a colonização.

(INEP/MEC, 2013a, p. 7)

A questão propõe que o aluno estabeleça relações interdiscursivas entre as produções artísticas, identificando elementos de continuidade (o retrato do início da colonização, tema retomado pelo Modernismo) e ruptura (a visão idealizada dos indígenas no texto do colonizador português, em contraposição à pintura mais "realista" de Portinari). Desse modo, avalia-se a habilidade de "reconhecer a presença de valores sociais e humanos atualizáveis e permanentes no patrimônio literário nacional" (MEC/INEP, 2013), que mobiliza o saber associar as obras ao seu momento histórico, bem como às intencionalidades e às características estilísticas dos movimentos a que se filiam.

\section{À GUISA DE CONCLUSÃO}

O ENEM 2013, no âmbito da literatura, apresenta um modelo avaliativo diferente do tradicionalmente realizado pelos exames vestibulares, em que a história literária costumava ser o foco da prova. O exame confere maior espaço aos textos literários, e a maior parte das questões mobiliza a compreensão leitora do estudante. Se bem que o espaço ocupado por essa esfera cultural possa ser considerado pequeno em relação a outros saberes disciplinares, é salutar que a prova apresente gêneros literários para leitura inclusive nas provas das outras áreas do conhecimento.

A concepção de leitura que subjaz ao exame supera os limites da falácia da intenção e da decodificação e a encara como um processo inferencial e interlocutivo, haja vista o modelo de leitor ativo pressuposto e as habilidades cognitivas mobilizadas pelas questões, tais quais ativação 
do conhecimento de mundo, inferências locais e globais. A perspectiva discursiva também perpassa algumas questões que relacionam os textos às suas condições de produção e interrogam sobre os efeitos de sentido promovidos pelos recursos linguísticos e expressivos.

No entanto, o tratamento dado à literatura nem sempre considera a perspectiva dos múltiplos letramentos literários. Consideradas as limitações de uma prova, podemos afirmar que o ENEM 2013 recobre a diversidade de autores, estilos, gêneros e movimentos, contemplando desde manifestações do período colonial à escrita teatral transgressora de Plínio Marcos. Há, inclusive, maior presença de escritores (e compositores) contemporâneos do que de clássicos, o que denota uma tentativa de aproximação à realidade cultural dos estudantes. Porém os letramentos representados são, sobretudo, os dominantes, que reverberam a visão beletrista da literatura, em detrimento dos discursos de resistência, da poesia matuta e dos cordéis, que formam o conjunto dos letramentos locais e vernaculares, social e culturalmente marginalizados.

Além disso, a maior parte das questões faz da literatura um anteparo para a abordagem de outros campos do conhecimento. As provas de humanidades e ciências, como foi visto, exploram a leitura literária como pretexto para o estudo de seus próprios objetos; ou os textos literários, como fator de contextualização dos saberes específicos ou, ainda, como fonte de compreensão textual, sendo que quaisquer outros textos de cunho pragmático poderiam se constituir em um meio para essa análise.

As questões da prova de linguagens e códigos, por sua vez, em sua maioria, ancoram-se nos gêneros literários para explorar aspectos linguísticos (macroestrutura semântica, função da linguagem, intencionalidade discursiva) e estilísticos (recursos expressivos, figura de linguagem) que também negligenciam a natureza literária do texto. Em quantidade menor, mas realizando uma avaliação de qualidade, encontram-se questões que efetivamente mobilizam o conhecimento da literatura (a leitura efetiva dos gêneros literários, considerando-se suas características discursivas) e sobre a literatura (reconhecimento do contexto de produção da obra, do projeto estético do autor e das escolas literárias, inclusive a partir do diálogo intersemiótico e entre obras de diferentes períodos).

O lugar ocupado pela literatura no ENEM 2013 está transitando entre uma abordagem diluída, a serviço de outros aspectos das ciências e da língua, e um tratamento pelo viés dialógico, a serviço da compreensão da literariedade dos textos, de sua representação cultural 
e de sua relação com outras semioses e produções de outros períodos. Esta perspectiva mais ampla só chegará às escolas se o professor, enquanto autor de suas aulas, proporcionar ao aluno o contato com os múltiplos letramentos literários e realizar a mediação pedagógica da leitura, oportunizando, sempre que for possível e necessário, o conhecimento acerca da história, da teoria e da crítica literária.

\section{REFERÊNCIAS}

ANDRADE, G. E. R. Literatura e ENEM: implicações no ensino médio. DLCV - Língua, Linguística \& Literatura, João Pessoa, v. 8, n. 2, p. 139-153, 2011. Disponível em: < http:/ /www. biblionline.ufpb.br/ojs/index.php/dclv/article/view/10786/7075>. Acesso em: 10 abr. 2014.

AZEVEDO, A. (1853). Lira dos vinte anos. São Paulo: Martin Claret, 1999.

BILAC, O. Poesias. (1888). Org. e pref. de Ivan Teixeira. São Paulo: Martins Fontes, 1997. . (1902). O caçador de esmeraldas. In: Poesias: antologia. São Paulo: Martin Claret, 2002. p. 37-55.

BRASIL. Orientações Curriculares para o Ensino Médio: linguagens, códigos e suas tecnologias. Brasília: Ministério da Educação, Secretaria de Educação Básica, 2006, vol 1.

2009. Ministério da Educação. Novo Enem. Disponível em: http://portal.mec.gov. br/index.php?Itemid=310+enen.br. Acesso em: 29 out. 2013.

CEREJA, W. R. Ensino de Literatura: uma proposta dialógica para o trabalho com a literatura. São Paulo: Atual, 2005.

COSSON, R. Letramento literário: teoria e prática. São Paulo: Contexto, 2009.

EBLE, L. J. Projeto movimentos atuais da literatura brasileira. Relatório de pesquisa parcial. Fundação Itaú Cultural, jun. de 2013.

FISCHER, L. A. et al. A Literatura no Exame Nacional do Ensino Médio (ENEM). Nonada Letras em Revista, Porto Alegre, ano 15, n. 18, p. 111-126, 2012.

GONZAGA, T. A. (1792). Marilia de Dirceu. 5 ed. São Paulo: Martin Claret, 2012.

GUIA de livros didáticos: PNLD 2012: Língua Portuguesa. Brasília: Ministério da Educação, Secretaria de Educação Básica, 2011.

INEP - Instituto Nacional de Estudos e Pesquisas Educacionais Anísio Teixeira. Exame Nacional do Ensino Médio (Enem): fundamentação teórico-metodológica. Brasília: INEP, 2005.

.; MEC. ENEM 2013: Prova de redação e de linguagens, códigos e suas tecnologias.

Prova de matemática e suas tecnologias. 2013a. Disponível em: < http://download.inep. gov.br/educacao_basica/enem/provas/2013/caderno_enem2013_dom_amarelo.pdf $>$. Acesso em: 10 jan. 2014.

_; __ ENEM 2013: Prova de ciências humanas e suas tecnologias. Prova de ciências da natureza e suas tecnologias. 2013b. Disponível em: < http://download.inep.gov. br/educacao_basica/enem/provas/2013/caderno_enem2013_sab_branco.pdf $>$. Acesso em: 10 jan. 2014.

JOUVE, V. Por que estudar literatura? São Paulo: Parábola, 2012.

MEC - Ministério da Educação/ INEP - Instituto Nacional de Estudos e Pesquisas Educacionais Anísio Teixeira. Edital do Exame Nacional do Ensino Médio- ENEM 2013. 2013. 
Disponível em: $<$ http://download.inep.gov.br/educacao_basica/enem/edital/2013/editalenem-2013.pdf>. Acesso em: 23 jan. 2014.

MEDEIROS, L. R. C. de. A que serve a literatura no Enem? In: ENCONTRO NACIONAL DE LITERATURA INFANTO-JUVENIL E ENSINO - ENLIJE, 2012, Campina GrandePB. Anais... Campina Grande-PB: Enlije, 2012. Disponível em: < http://editorarealize .com.br/revistas/enlije/trabalhos/f66302745ea14ff35a9fd58c762b419f_861_432_.pdf>. Acesso em: 23. jan. 2014.

MOITA LOPES, L. P. da. Da aplicação de Linguística à Linguística Aplicada indisciplinar. In: R. C. PEREIRA; P. ROCA (Orgs.). Linguistica aplicada: um caminho com diferentes acessos. São Paulo: Contexto, 2009, p. 11-24.

PAULINO, G.; COSSON, R. Letramento literário: para viver a literatura dentro e fora da escola. In: R. ZILBERMAN; T. RÖSING (Orgs.). Escola e leitura: velha crise; novas alternativas. São Paulo: Global, 2009, p. 61-81.

PIETRI, E. de. Os estudos de linguagem e o ensino de Língua Portuguesa no Brasil. In: SIGNORINI, I.; FIAD, R. S. (Orgs.). Ensino de lingua: das reformas, das inquietações e dos desafios. Belo Horizonte: Editora da UFMG, 2012, p. 18-37.

PINHEIRO, H. Reflexões sobre o livro didático de literatura. In.: MENDONÇA, M.; BUNZEN, C. (Orgs.). Português no ensino médio e formação do professor. São Paulo: Parábola, 2006, p. 103-116.

RANGEL, E. Literatura e livro didático no ensino médio: caminhos e ciladas na formação do leitor. In: PAULINO, G.; MARTINS, A. A.; PAIVA, A.; VERSIANI, Z. (Orgs.). Leituras literárias: discursos transitivos. Belo Horizonte: Autêntica, 2005, p. 145-162.

ROJO, R. Letramentos múltiplos, escolar e inclusão social. São Paulo: Parábola, 2009.

ROSA, C. M. Letramento Literário. Revista Acolhendo a Alfabetização nos Países de Lingua Portuguesa, Brasil, SP, v. 1, n. 11, p. 188-195, set. 2011. Disponível em: < http://www. acoalfaplp.net>. Acesso em: 13 mai. 2014.

ROUXEL, A. Aspectos metodológicos do ensino da literatura. In.: DALVI, M. A.; REZENDE, N. L. de; JOVER-FALEIROS, R. (Orgs.). Leitura de literatura na escola. São Paulo: Parábola, 2013, p. 17-33.

SOARES, M. Letramento: um tema em três gêneros. Belo Horizonte: CEALE/Autêntica, 2001.

Português na escola. História de uma disciplina curricular. In: BAGNO, M. (Org.).

Linguistica da Norma. 2. ed. São Paulo: Loyola, 2004, p. 155-177.

. Ler, verbo transitivo. In.: PAULINO, G.; MARTINS, A. A.; PAIVA, A.; VERSIANI, Z. (Orgs.). Leituras literárias: discursos transitivos. Belo Horizonte: Autêntica, 2005, p. 29-34.

SOUZA, R. J.; COSSON, R. Letramento literário: uma proposta para a sala de aula. São José do Rio Preto: Objetos educacionais do acervo digital da Unesp: 2011. Disponível em: < http://www.acervodigital.unesp.br/bitstream/123456789/40143/1/ 01d16t08.pdf>. Acesso em: 13 mai. 2014.

\section{NOTAS}

${ }^{1}$ Rosa (2011) atribui o primeiro uso do termo a Graça Paulino, que o mencionou no texto "Funções e disfunções do livro para crianças", publicado em O jogo do Livro Infantil (1997), e o divulgou na Associação Nacional de Pós-Graduação e Pesquisa em Educação (ANPED), com o trabalho "Letramento Literário: cânones estéticos e cânones literários" (1999). 
${ }^{2}$ Também por meio da literatura se podem aprender história, geografia, cultura etc., mas Cosson (2009) destaca a possibilidade de o professor, pela literatura, conduzir o educando no processo de apropriação e construção dos sentidos de um discurso que significa por meio das próprias palavras.

${ }^{3} \mathrm{~A}$ escolha desse corpus de análise atende às limitações espaciais de nosso trabalho e se justifica pelo fato de outros estudiosos terem se dedicado à análise das provas anteriores, como veremos no item 3.

${ }^{4}$ Com base na perspectiva dos letramentos múltiplos defendida por Rojo (2009), pretendemos verificar que letramentos são contemplados: se apenas os socialmente valorizados, estabelecidos no cânone normalmente adotado nas escolas, ou se também os letramentos locais, vernaculares, e, neste caso, em que proporção.

${ }^{5}$ Por exemplo, os poemas (auto)irônicos de Álvares de Azevedo ([1853]1999), como É Ela! É Ela! É Ela! É Ela!, que zombam da idealização romântica, e algumas liras da II parte de Marília de Dirceu, de Tomás Antônio Gonzaga ([1792]2012), que antecipam o Romantismo.

${ }^{6}$ Bilac, por exemplo, é categorizado como parnasiano, mas também escreveu obras de viés romântico - Via Láctea ([1888]1997) - e simbolista - Caçador de Esmeraldas ([1902]2002).

${ }^{7}$ Ainda que tais gêneros não sejam tomados como objetos de ensino, eles são experienciados nas atividades de leitura informativa e são abordados pelos profissionais especializados em seu domínio discursivo, como o professor de matemática, que explora os gráfico, e o de geografia, que trabalha com mapas. Quanto aos textos literários, o professor de português é o único que tem formação específica para analisá-lo.

${ }^{8}$ Houve mudanças significativas no perfil da prova em 2009, quando as questões passaram a ser divididas por área. A matriz curricular também sofreu modificações, com a indicação de competências para cada área, a ampliação do número de habilidades específicas e a apresentação dos objetos de conhecimento. Por isso, não iremos nos deter às considerações dos autores acerca das provas anteriores a 2009.

${ }^{9}$ Embora os autores não definam o que entendem por "conhecimento literário”, é possível subentender que eles se referem ao saber sobre a literatura, isto é, ao manejar conceitos da teoria, da crítica ou da historiografia literária para interpretar os textos.

${ }^{10}$ Os autores consideraram literários quaisquer textos que promovessem fruição estética.

${ }^{11}$ Diferentemente das pesquisas citadas, não consideramos os quadrinhos como literatura. Ainda que favoreçam a fruição estética e materializem a função poética da linguagem, eles servem a outros propósitos comunicativos, como provocar o riso, quebrar expectativas, gerar o humor, divertir e entreter.

${ }^{12}$ A canção é um gênero que transita entre as esferas musical e literária e se aproxima bastante da poesia, haja vista o uso da métrica, das rimas e da linguagem figurada, entre outras características discursivas.

${ }^{13}$ Incluímos apenas os exemplares desses gêneros que tematizam o universo literário ou alguma obra específica, exigindo do aluno um determinado saber da/sobre a literatura.

${ }^{14}$ As provas analisadas (caderno branco e caderno amarelo) encontram-se disponíveis em $<$ http://portal.inep.gov.br/web/enem/edicoes-anteriores/provas-e-gabaritos $>$. Acesso em: 10 jan. 2014.

${ }^{15}$ Classificamos como romance o excerto de Os sertões, apesar da dificuldade de categorização dessa narrativa, que até hoje desafia a crítica. 


\begin{abstract}
${ }^{16}$ Estabelecemos aqui a carta como gênero literário para nos referirmos a dois exemplares do texto de Caminha, que, embora não seja literário, faz parte do primeiro conjunto de registros escritos sobre o Brasil.
\end{abstract}

${ }^{17}$ A questão 98 (INEP/MEC, 2013a, p. 7) traz um fragmento da peça, de Plínio Marcos, permeada de marcas do português brasileiro ("Então desce ele"), do léxico e da sintaxe popular ("sacana", "só que", "sarará"), porém só avalia a função da repetição, sem levar em conta como tais elementos, por via da figuratividade linguística, contribuem para a construção verossímil do espaço ficcional da delegacia e da imagem das personagens (LUNA, 2014).

${ }^{18}$ As questões 105 (INEP/MEC, 2013a, p. 9) e 114 (INEP/MEC, 2013a, p. 12) também avaliam a leitura da literatura, requerendo apenas a compreensão da macroestrutura semântica do poema Olá! Negro, de Jorge de Lima, e do ensaio crítico, respectivamente, como se observa nos enunciados: "105. O conflito de gerações e de grupos étnicos reproduz, na visão do eu lírico, um contexto assinalado por [...]", "114. A autora descreve a importância da manta para aquela família, ao verbalizar que "novas e antigas histórias foram sendo incorporadas à manta mais valiosa do mundo'. Essa valorização evidencia-se pela [...]”.

${ }^{19}$ A imagem de uma personagem humilde é construída desde a nomeação, passando pelo trabalho braçal, até o uso da fala popular e socialmente estigmatizada.

Recebido: 28/05/2014

Aprovado: 06/04/2015

Contato:

Universidade Federal Rural de Pernambuco Departamento de Educação Rua Dom Manoel de Medeiros, s/n, Dois Irmãos Recife |PE | Brasil

CEP 52.171-900 